\title{
The Cascade of Chaos:
}

\section{From Early Adversity to Interpersonal Aggression}

\author{
Aurelio José Figueredo* \\ Department of Psychology, School of Mind, Brain, and Behavior, \\ College of Science, University of Arizona
}

Candace Jasmine Black

Department of Psychology, School of Social and Behavioral Sciences, New College of Interdisciplinary Arts and Sciences, Arizona State University

\author{
Emily Anne Patch
}

Department of Psychological Sciences, Northern Arizona University

Nadja Heym

Department of Psychology, Nottingham Trent University

\author{
José Henrique Benedetti Piccoli Ferreira \\ Marco Antônio Corrêa Varella \\ Renata Pereira de Felipe
}

Departamento de Psicologia Experimental, Universidade de São Paulo

Leonardo Antonio Marui Cosentino 
Instituto de Ciências Humanas - Psicologia, Universidade Paulista

Coordenação Ensino Médio, Escola Móbile

Felipe Nalon Castro

Departamento de Fisiologia e Comportamento, Universidade Federal do Rio Grande do

Norte

Jean Carlos Natividade

Departamento de Psicologia, Pontifícia Universidade Católica do Rio de Janeiro

Wallisen Tadashi Hattori

Faculdade de Medicina, Universidade Federal de Uberlândia

Marisol Pérez-Ramos

Departamento de Sociologìa, Universidad Autónoma Metropolitana-Iztapalapa

Guy Madison

Institutionen för Psykologi, Umeå Universitet

Heitor Barcellos Ferreira Fernandes

Department of Psychology, School of Mind, Brain, and Behavior,

College of Science, University of Arizona 
*Corresponding Author: Aurelio José Figueredo, PhD, Department of Psychology, 1503 East University Boulevard, School of Mind, Brain, and Behavior, College of Science, University of Arizona, Tucson, Arizona, USA 85721-0068; Telephone: 520-621-7444; Email:

ajf@email.arizona.edu 
Running Head: THE CASCADE OF CHAOS

\section{The Cascade of Chaos:}

\section{From Early Adversity to Interpersonal Aggression}

\section{Abstract:}

We developed a cascade model to reconstruct the hypothesized developmental progression from (1) increased resource instability during childhood to (2) decreased maternal sensitivity during childhood to (3) social vulnerability cognitive schemata to (4) faster life history strategies to (5) decreased behavioral regulation to (6) more pronounced "Dark Triad" personalities to (7) higher levels of interpersonal aggression in adulthood. The hypothesized cascade model also evaluated the cross-cultural generality of this theoretically-specified developmental progression across a sampling of different societies: (1) the United States of America (N=144); (2) Mexico (N=118); (3) Brazil (N=1091, distributed across 3 data collection sites); (4) Sweden ( $N=144)$; and (5) the United Kingdom $(\mathrm{N}=260)$. Out of 21 interactive tests of the cross-cultural robustness of the main model parameters, only five reached statistical significance, and were relatively small in magnitude compared to their main effects. In no case did the magnitude and direction of the interaction completely reverse that of the corresponding main effect of the predictor, but merely either augmented or attenuated it somewhat across the affected study sites. We conclude that the results generally supported both the configural and metric invariance of the cascade model to a relatively high, albeit imperfect, degree.

\section{Keywords:}

Early Adversity, Life History Strategy, Behavioral Regulation, Dark Triad Traits, Interpersonal Aggression

Public Significance Statement: This cross-cultural study tested the generality of a developmental sequence leading from childhood harshness and unpredictability, through various theoretically specified stages, to adult interpersonal aggression. 


\section{The Cascade of Chaos:}

\section{From Early Adversity to Interpersonal Aggression}

\section{Rationale for Study}

The purpose of this study was to reconstruct, model, and estimate a developmental sequence from retrospective self-report, starting with the experience of early environmental adversity and ultimately leading to the involvement in interpersonal aggression. As illustrated by Figure 1, the multiple-mediation cascade model hypothesized a sequence of successive stages of development based on Life History (LH) theory from (1) increased resource instability during childhood to (2) decreased maternal sensitivity during childhood to (3) social vulnerability cognitive schemata to (4) faster life history strategies to (5) decreased behavioral regulation to (6) more antagonistic social schemata to (7) higher levels of involvement in interpersonal aggression during adulthood. This study does not address the victimization dimension of aggressive interactions, but only focuses on perpetration.

[Insert Figure 1 Here]

In addition, the present study attempts to establish the cross-cultural robustness of these findings by examining the degree of structural and metric invariance of both measurement and structural models across various data collection sites in the United States of America, Mexico, Brazil, Sweden, and the United Kingdom. Thus, it explores how chaotic early environments replicate themselves intergenerationally by influencing developmental, emotional, psychological, and behavioral characteristics of children exposed to early adversity. An unfortunate effect of such exposure is that, for some, it creates conditions conducive to the development of similar patterns of behavior, thereby facilitating intergenerational transmission of chaotic patterns of behavior.

\section{Description of Major Constructs}


LH theory describes the strategic allocation of bioenergetic and material resources in service of survival and reproduction in each phase of life (Black, Figueredo, \& Jacobs, 2018; Figueredo, Patch, \& Ceballos, 2015). LH strategies range from fast to slow, where slow strategies are reflected in characteristics indicating greater somatic and parental effort relative to mating effort. In contrast, fast strategies are characterized by greater mating and intrasexually competitive effort relative to somatic and parental effort.

Individual plasticity in the context of LH theory is mainly shaped by specific dimensions of environmental risk: harshness and unpredictability (Ellis et al., 2009). Rates of morbidity/mortality and resource scarcity characterize environmental harshness, while variation of harshness over time and space characterize instability. Environmental unpredictability, particularly for juveniles, accelerates developmental timing and maturation, because unpredictability in the environment poses risks to survival and reproduction. Accelerating development to become reproductive increases fitness in the face of such risks. Based on the LH theoretical framework, step 1 in the cascade model assessed environmental instability by measuring economic resource instability, including unpredictable access to food, clothing, and other basic necessities. Step 2 assessed measured maternal sensitivity, as environmental unpredictability creates competing interests for parents raising offspring under these conditions (Belsky, Schlomer, \& Ellis, 2012). Given the significant impact of parental investment on offspring developmental outcomes (Cabeza de Baca \& Ellis, 2017; Cabeza de Baca, Figueredo, \& Ellis, 2012; Cabeza de Baca, Sotomayor-Peterson, Smith-Castro, \& Figueredo, 2014; Cabeza de Baca, Sotomayor-Peterson, \& Figueredo, 2017; Cabeza de Baca, Wahl, Bartnett, Figueredo, \& Ellis, 2016; Sotomayor-Peterson, Cabeza de Baca, SmithCastro, \& Figueredo, 2012), our cascade model measured maternal sensitivity along three dimensions following Belsky et al.'s (2012) work: (1) supportive presence, (2) respect for autonomy, and (3) hostility. 
Evolutionary psychologists apply LH to interpret the shared variance of a variety of personality, cognitive, emotional, and behavioral traits that are impacted by environmental risk factors (Figueredo et al., 2006; 2007). Step 3 in the cascade assessed internalized schemata of social vulnerability. Assessing how individuals internalize external events is an important argument in favor of measuring psychological LH characteristics in addition to biodemographic ones (Black, Figueredo, \& Jacobs, 2017; Black, Patch, Figueredo, \& Jacobs, under revision). An evolutionary analysis of the development of social deviance has elucidated the mechanisms by which social and sexual environments selecting for slow LH lead to the internalizing of convergent or mutualistic social schemata, whereas those selecting for fast LH lead to the internalizing of divergent or antagonistic social schemata, as working models for their social and sexual relationships (Figueredo \& Jacobs, 2010). Based on the operationalization of environmental instability, we assessed three dimensions of social vulnerability cognitive schemata in step 3: (1) abandonment/instability, (2) mistrust/abuse, and (3) vulnerability to harm (Young, 1999).

According to the theoretical dynamics of LH theory (Ellis et al., 2009), high childhood resource instability, low childhood maternal sensitivity, and the consequent development of an social vulnerability social cognitive schema should contribute to the development of a faster LH strategy to be expressed in adulthood, which constitute step 4. LH strategy is conceived of as a psychometric composite of three major constituents (the Super-K Factor; Figueredo et al., 2004, 2007): (1) the K-Factor, representing slow life history strategy, as measured psychometrically by a set of convergent behavioral and cognitive indicators; (2) the Covitality Factor, indicating the higher mental and physical functioning reflective of increased received parental and invested somatic effort; and (3) the Personality Factor (also known as the General Factor of Personality or GFP), constructed from the 
constituent Big Five (Openness to Experience, Conscientiousness, Extraversion, Agreeableness, and Emotional Stability, which is the inverse of Neuroticism).

Behavioral dysregulation constitutes step 5 the sequence within the cascade model. Resource instability in childhood appears to decrease behavioral regulation in adulthood (Hackman, Farah, \& Meaney, 2010; Hill, Prokosch, DelPriore, Griskevicius, \& Kramer, 2016; Griskevicius et al., 2013; Griskevicius, Tyber, Delton, \& Robinson, 2011). Detecting environmental instability in childhood decreases one's sense of control, which has been shown to mediate the relationship between environmental conditions and impulsive behavior (Mittal \& Griskevicius, 2014). Impulsive behavior developed in adolescence increases the risk of aggression, crime, and other reckless behaviors (Ellis et al., 2012).

Dark Triad (DT) personalities tend to be more common amongst faster LH strategists (Book \& Quinsey, 2004; Schmitt et al., 2017; Jonason, Icho, \& Ireland, 2016; Patch \& Figueredo, 2017). DT personalities apparently constitute psychological adaptations that make individuals more capable of achieving their antagonistic ends. For example, these traits have been linked to exploitative mating styles (Jonason, Norman, Webster, \& Schmitt, 2009), social dominance and non-conformity (Figueredo \& Jacobs, 2010) and aggression (Keller et al., 2014). In step 6 of the sequence of the cascade model we therefore examine antagonism, the core of the DT traits (Figueredo, Patch, Perez-Ramos, \& Cruz, 2018; Jones \& Figueredo, 2011).

There are on-going debates about whether or not psychopathy, Narcissism, and Machiavellianism are different personality traits (Figueredo, Gladden, Sisco, Patch, \& Jones, 2015; Jonason, Icho, \& Ireland, 2016; Paulhus \& Williams, 2002), and here we refer to the DT personalities as individuals who have a core of callousness and an antagonistic manner of interacting with the world (Figueredo, Patch, Perez-Ramos, \& Cruz, 2018). While the DT personalities do have a common core of callousness (Jonason et al., 2009; Jones \& Figueredo, 
2013; Jones \& Paulhus, 2011), it is generally accepted that they have some unique features (Heym, Firth, Kibowski, Sumich, Egan, \& Bloxsom, 2019). Psychopaths are characterized by unplanned, erratic, impulsive behavior (Jones \& Paulhus, 2011), while Machiavellians maintain an ability to plan for the long-term (Jonason, Icho, \& Ireland, 2016; Jones \& Paulhus, 2011; Paulhus \& Williams, 2002). Narcissists are characterized by grandiose sense of self and extreme entitlement (Jones \& Paulhus, 2011).

The Dark Inventory (DI; Figueredo, Patch, Perez-Ramos, \& Cruz, 2018) represents a theoretical restructuring that reorganizes the variance among these DT traits into three constructs: (1) antagonistic social schemata; (2) mutualistic social schemata; and (3) emotional and cognitive lability. Here, the antagonistic construct refers to the DT's common core of callousness and lack of emotional empathy. The functional opposite of this is mutualistic, which refers to the ability to form attachments and have concern for other individuals. Lability refers to these individuals' inability to regulate their behavior (Figueredo et al., 2018). Thus, the DT traits have been associated with a range of direct and indirect interpersonal aggressive behaviors (e.g., Heym et al., 2019), which form the final outcome (Step 7) of the Cascade model.

If an antagonistic social schema is an adaptation, it should be at least partially heritable (Croston et al., 2015). The heritable nature of psychopathy (Millon et al., 2002; Beitchman et al., 2012) and LH strategy (Figueredo et al., 2006) might have been selected for the benefits of deviant behaviors, such as social cheating (Book \& Quinsey, 2004). These adaptations are identifiable, for example, in that psychopaths have dysregulated autonomic responses, fail to recognize fear stimuli, and develop inappropriate responses to these stimuli (Dadds et al., 2012) Their diminished fear response, underpinned by underactivity or dysregulation in the limbic system (Blair, 2003; Kiehl, 2006), prevents them from learning to avoid dangerous stimuli, and has been argued to underpin the aggressive and violent behavior 
in psychopathy (Blair, 2003). From a developmental viewpoint, children as young as 7 years demonstrate callous-unemotional (CU) traits linked to lack of guilt, empathy and concern for others, as well as limbic dysregulation (Dadds et al., 2012; Viding, Blair, Moffitt, \& Plomin, 2014), all of which are thought to pose a developmental risk for psychopathy in adulthood (Viding et al., 2005). These traits are strongly heritable (around $67 \%$ or $81 \%$ when coupled with conduct disorder; Dadds et. al., 2013). Importantly, while environmental factors such as abuse and neglect can cause aggression and conduct problems, not all children with psychopathic tendencies have experienced any abuse (Dadds et al., 2012). However, despite genetic influences, psychopathy has a greater observed prevalence in unfavorable environments (Viding et al., 2014). Thus, our developmental cascade model examines levels of instability in the childhood environment and the resulting psychological risk factors, and fast LH strategy as risk factors for the development of DT traits and an antagonistic social schemata and proclivity to be involved in violent interactions, which constitutes step 7 in our model. The current study conceptualized this broadly across five different manifestations of aggression towards both same-sex and opposite-sex targets (Figueredo, Jacobs, Gladden, Bianchi, Patch, Beck, Kavanagh, Sotomayor-Peterson, Jiang, \& Li, 2017): (1) Coercive Control, (2) Psychological Abuse, (3) Physical Abuse, (4) Escalated (Life Threatening) Violence, and (5) Sexual Abuse.

Consistent with one of the major goals of evolutionary psychology, which is to identify and document human universals, we also subjected this cascade model to tests of cross-cultural robustness across five different contemporary societies.

\section{Overview of Study}

In summary, the present study was designed to reconstruct, model, and estimate the hypothesized developmental progression from (1) increased resource instability during childhood to (2) decreased maternal sensitivity during childhood to (3) social vulnerability 
cognitive schemata to (4) faster LH strategies to (5) decreased behavioral regulation to (6) more pronounced "Dark Triad" personalities to (7) higher levels of interpersonal aggression. Further, the present study was designed to evaluate the cross-cultural generality of this hypothesized developmental progression across a sampling of different societies: (1) the United States of America; (2) Mexico; (3) Brazil; (4) Sweden; and (5) the United Kingdom.

\section{METHODS}

\section{Participants}

University students were recruited at the following institutions, the demographics listed in Table 1: (1) University of Arizona in the US; (2) Umeå Universitet in Sweden; (3) the Autonomous Metropolitan University of Mexico; (4) Nottingham Trent University in the UK; and (5) the Universidade de São Paulo, Universidade Federal do Rio Grande do Norte, and Universidade Federal do Rio Grande do Sul in Brazil. The Brazilian samples were broken down by student place of origin within Brazil in our analyses, rather than the site of their data collection. For the final composite sample size of $N=1660$, after excluding all cases with missing data, a post hoc power analysis revealed probabilities of Type II Error of $p$ $<.01$ for $r=.2, r=.3$, and $r=.5$.

Participants were recruited primarily from introductory Psychology classes, in which case site administrators were invited to classrooms to announce the project and instruct the students on how to find the data collection website. Participants from the University of Arizona could also sign up through their respective Psychology department's subject pool in exchange for course or extra credit. The Swedish and British research teams used a raffle system to recruit students from all disciplines. Following the University of Arizona policy regarding raffles for subject recruitment, the recruitment materials abroad did not reference any compensation. In Brazil, research participants are prohibited from receiving any compensation. Consent materials included information about the raffle and stated that 
participation was not required to participate in the drawing; additionally, students were provided with a way to decline participation but enter the drawing. For all five countries sampled, we also followed all other pertinent IRB regulations for the protection of human research participants.

\section{[Insert Table 1 Here]}

\section{Procedures}

For the following three samples, the study was conducted online using the University of Arizona's Qualtrics (Provo, UT) online data collection system: (1) University of Arizona, (2) University of Umeå, and (3) Autonomous University of Mexico. For the British sample (i.e., Nottingham Trent University), data were collected using an online data collection system similar to Qualtrics, called the Bristol Online Survey. For the Brazilian samples, data were collected online using SurveyMonkey, Inc. (San Mateo, CA).

Participants provided informed consent and completed the questionnaires via secure data collection software. All research participants received unique subject IDs that do not identify them as individuals. Participants across the five countries (Brazil, Mexico, Sweden, UK, and US) completed all the questionnaires listed below.

\section{Measures}

All questionnaires were translated and culturally adapted to each country's language by bilingual researches using the standard back-translation procedure for cross-cultural research (Brislin, 1970). As all of the measures used have been published previously, we restrict the present treatment to a listing of scales plus the citations for each, leaving the full descriptions of each measure to Appendix A:

\section{- Environmental Instability}

- Early Environment Questionnaire (Black \& Gable, 2012). 
- Young Schema Questionnaire - Abbreviated Short Form (YSQ-S2; Young \& Brown, 1999; Figueredo et al., 2017).

\section{- Higher-Order LH (Super-K)}

- Mini-K Short Form (Figueredo et al., 2006).

○ Rand 36 Item Health Survey: Version 1 (Ware \& Sherbourne, 1992).

- Ten-Item Personality Inventory (TIPI; Gosling et al., 2003).

\section{- Behavioral Regulation}

- The Behavioral Regulation Scale (BRIEF; Gioia, Isquith, Retzlaff, \& Espy, 2002).

\section{- Dark Triad Personalities}

○ The Dark Inventory (DI; Figueredo, Patch, Perez-Ramos, \& Cruz, 2018).

\section{- Interpersonal Aggression (IPA).}

- Interpersonal Relations Rating Scale (IRRS; Figueredo, Jacobs, Gladden, Bianchi, Patch, Beck, Kavanagh, Sotomayor-Peterson, Jiang, \& Li, 2018; Figueredo, Patch, Perez-Ramos, \& Cruz, 2018).

Psychometric reliabilities and validities for each of these scales is presented in Table 2, which displays the Cronbach's alphas and part-whole correlations (unit-weighted factor loadings) for all the major constructs used in these analyses. All these measurement model parameters were deemed to be psychometrically acceptable.

[Insert Table 2 Here]

Due to the high degree of cross-cultural invariance among the results of these measurement models, the ones presented here are aggregated statistics, with the disaggregated equivalents by study site presented in Appendix B.

\section{Statistical analyses}


All univariate and multivariate analyses were performed using SAS 9.4 (SAS Institute Inc., 2015) and Unimult 2 (Gorsuch, 2016). Using SAS PROC STANDARD and DATA, unit-weighted common factor scales (Gorsuch, 1983) were estimated as the means of the standardized scores for all non-missing subscales on each factor (Figueredo, McKnight, McKnight, \& Sidani, 2000). Using SAS PROC CORR, we also computed the Cronbach's alphas, the covariance matrices of the subscales, and the part-whole correlations of the subscales with the unit-weighted factor scales. All the unit-weighted factor scales estimated were entered as manifest variables for causal analysis within a cascade model framework (Davis et al., 2007; Demetriou et al., 2002; Figueredo \& Gorsuch, 2007; Guggenheim, Davis, \& Figueredo, 2007; Mouyi, 2006).

The cascade model was constructed as a series of hierarchical multiple regressions, using UniMult 2, in which each prior criterion variable was entered as the first predictor variable for each successive equation. This had the function of statistically controlling for all indirect effects of the predictor variables through each prior criterion, so that each regression model would be limited to the estimation of the direct effects of each successive set of predictors without confounding by the indirect effects through prior the criterion variables. Thus, if X1 predicted Y1 and Y1 then predicted Y2, then the second equation would be able to estimate the direct effect of $\mathrm{X} 1$ on $\mathrm{Y} 2$ while statistically controlling for its indirect effect on Y2 through Y1. Thus, the theoretically-determined sequence of criterion variables was specified as follows, along with the expected direction of each successive effect given in parentheses: Resource Instability during Childhood $(-) \rightarrow$ Maternal Sensitivity during Childhood (-) $\rightarrow$ Social Vulnerability Cognitive Schemata $(-) \rightarrow$ Super-K (Slow LH) Factor $(+) \rightarrow$ Behavioral Regulation $(-) \rightarrow$ Dark Inventory of "Dark Triad" Traits $(+) \rightarrow$ Interpersonal Aggression. 
To test for the cross-cultural consistency of these effects, a system of orthogonal contrasts was constructed to operationalize the differences between the different study populations. The contrasts were constructed based on simple geography rather than the environmental factors of "harshness and unpredictability" (Ellis et al., 2009) that are theoretically predicted to influence life history evolution and development. These latter factors are measured explicitly in the model by individual-level constructs and are not encapsulated in the system of orthogonal contrasts. These contrasts were intentionally designed to be agnostic with respect to our main hypotheses in view of the fact that although our sampling of individuals was extensive, our sampling of different cultures (only 5 different national polities) was hardly sufficient to support any generalizable inferences regarding the possible causes of the cross-cultural differences. Even had we explicitly based our contrasts on comparing cultures with high- to low- harshness or unpredictability, our sample size of cultures would have been inadequate to make such causal attributions in a way that would be generalizable to other cultures not sampled.

The first contrast (C1) compared the societies sampled in the Americas with those sampled in Europe. The second contrast (C2) compared North America (USA and Mexico) to South America (Brazil). The next two contrasts were North-South comparisons within each continent. The third contrast (C3) compared the USA to Mexico, within North America. The fourth contrast (C4) compared Sweden to the United Kingdom, within Europe. The remaining four contrasts compared subnational regions within Brazil. The fifth contrast (C5) compared Northern Brazil (Acre, Amapá, Amazonas, Pará, Rondônia, Roraima, Tocantins, Alagoas, Bahia, Ceará, Maranhão, Paraíba, Pernambuco, Piauí Rio Grande do Norte, Sergipe) to Southern Brazil (Distito Federal, Goiás, Mato Grosso, Mato Grosso do Sul, Espírito Santo, Minas Gerais, Rio de Janeiro, São Paulo, Paraná, Rio Grande do Sul, Santa Catarina). The sixth contrast (C6) compared the North of Brazil (Acre, Amapá, Amazonas, Pará, Rondônia, 
Roraima, Tocantins) to the Northeast of Brazil (Alagoas, Bahia, Ceará, Maranhão, Paraíba, Pernambuco, Piauí Rio Grande do Norte, Sergipe). The seventh contrast (C7) compared the Southeast (Espírito Santo, Minas Gerais, Rio de Janeiro, São Paulo) to the remainder of the Southern regions (Distito Federal, Goiás, Mato Grosso, Mato Grosso do Sul, Paraná, Rio Grande do Sul, Santa Catarina). The eighth contrast (C8) compared the Center West (Distito Federal, Goiás, Mato Grosso, Mato Grosso do Sul) to the furthest South (Paraná, Rio Grande do Sul, Santa Catarina).

These orthogonal contrasts were entered first as main effects, to test and adjust for cross-cultural differences in baselines for each criterion variable. Interaction terms were then constructed for each predictor variable (including the prior criterion variables) within each regression to assess the degree of conditionality of the effects of each predictor upon the sites sampled. This procedure enabled us to estimate of the degrees of cross-cultural consistency of each effect within the model by comparing the magnitudes and direction of the interactions to those of the main effects.

To statistically protect against alpha slippage (inflation of the Type I Error rate), each set of contrasts and contrast interactions was assessed setwise by an omnibus protective Fratio. Thus, if this omnibus test was not statistically significant for any given set of contrasts or contrast interactions, the individual terms within each set were not examined for statistical significance and the entire set was considered nonsignificant as a whole. This controlled for excessive alpha slippage by reducing the functional number of significance tests (Cohen \& Cohen, 1983).

\section{RESULTS}

Magnitudes and directions of statistically significant effects are reported below in parentheses, operationalized as either the multiple correlation coefficients $(R)$ or the semipartial correlation coefficients $(s R)$, and followed by the probability under the null 
hypothesis (e.g., $p<.05)$. The magnitudes of certain non-significant protective omnibus tests are also reported to highlight their relatively small effect sizes. The full details of the series of hierarchical multiple regressions (Cascade Equations 1-7) used to operationalize the structural hypotheses and test for cross-cultural consistency, including all statistically nonsignificant effects are reported in Tables C1-C7 in Appendix C.

Instability of Childhood Economic Resources (Cascade Equation 1, $R=.26, p=.00$ )

The omnibus F-ratio for the set of main effects of the orthogonal contrasts for crosscultural sites was statistically significant $(R=.26, p=.00)$. This indicates that it was appropriate to evaluate and interpret the statistical significance of the individual terms within that set as representing baseline differences in the Instability of childhood economic resources across certain sites. Four individual contrasts were found statistically significant, indicating that the baseline level of Childhood Resource Instability was: (C1) higher in the Americas than in Europe $(s R=.19, p=.00)$; (C2) lower in North than South America $(s R=-.13$, $p=.00)$; (C3) lower in the USA than in Mexico $(s R=-.09, p=.00)$; and (C7) higher in the Southeast than in other Southern regions of Brazil $(s R=.06, p=.01)$.

Maternal Sensitivity during Childhood (Cascade Equation 2, $R=.24, p=.00)$

The main effect of childhood Resource Instability upon childhood Maternal Sensitivity was statistically significant and negative $(s R=-.21, p=.00)$. The omnibus F-ratio for the set of main effects of the orthogonal contrasts for cross-cultural sites was not statistically significant $(R=.05, p=.74)$, suggesting that this variable was statistically invariant among study sites.

However, the omnibus F-ratio for the set of interactive effects of the orthogonal contrasts for cross-cultural study sites with childhood Resource Instability was statistically significant $(R=.12, p=.00)$, permitting us to safely evaluate and interpret the individual interaction terms. Two interaction terms between the contrasts and childhood Resource 
Instability were found statistically significant, indicating that the effect of childhood Resource Instability on childhood Maternal Sensitivity was: (C1) higher in the Americas than in Europe $(s R=.09, p=.00)$; and (C2) lower in North than South America $(s R=-.05, p=.04)$. However, these effects were both smaller in absolute magnitude than the main effect of childhood Resource Instability so that in neither case were the directions of that main effect reversed, just either somewhat augmented or attenuated in the affected sites.

Social Vulnerability Cognitive Schemata (Cascade Equation 3, $R=.46, p=.00)$

In line with the model, the main effect of childhood Maternal Sensitivity upon childhood Social Vulnerability Cognitive Schemata was statistically significant and negative $(s R=-.35, p=.00)$, whereas the main effect of childhood Resource Instability upon childhood Social Vulnerability Cognitive Schemata was statistically significant and positive $(s R=.10$, $p=.00)$.

The omnibus F-ratio for the set of main effects of the orthogonal contrasts for crosscultural sites on childhood Social Vulnerability Cognitive Schemata was statistically significant $(R=.28, p=.00)$. Three contrast main effects were statistically significant, indicating that the baseline level of childhood Social Vulnerability Cognitive Schemata was: (C1) lower in the Americas than in Europe $(s R=-.21, p=.00)$; (C2) higher in North America than South America $(s R=.13, p=.00)$; and $(\mathrm{C} 4)$ lower in Sweden than in the United Kingdom $(s R=-.12, p=.00)$.

Nevertheless, the omnibus F-ratios for the sets of interactive effects of the orthogonal contrasts for cross-cultural sites with both childhood Maternal Sensitivity $(R=.06, p=.48)$ and childhood Resource Instability $(R=.05, p=.62)$ were not statistically significant for Social Vulnerability Cognitive Schemata showing statistical invariance across study sites for the effects of these two predictor variables.

Super-K (Slow LH) Factor (Cascade Equation $4, R=.46, p=.00$ ) 
As expected, the main effect of childhood Social Vulnerability Cognitive Schemata upon adult Slow LH Strategy, as measured by the Super-K Factor, was statistically significant and negative $(s R=-.37, p=.00)$, whereas the main effect of childhood Maternal Sensitivity upon adult Slow LH Strategy was statistically significant and positive $(s R=.21$, $p=.00)$. As specifically predicted by LH theory, the main effect of childhood Resource Instability upon adult Slow LH Strategy was statistically significant and negative $(s R=-.08$, $p=.00)$.

The omnibus F-ratio for the set of main effects of the orthogonal contrasts for crosscultural sites upon adult Slow LH Strategy was statistically significant $(R=.10, p=.01)$. Two contrast main effects were statistically significant, indicating that the baseline level of adult Slow LH Strategy was: (C3) higher in the USA than in Mexico $(s R=.07, p=.00)$; and (C7) higher in the Southeast than in other Southern regions of Brazil $(s R=.06, p=.01)$.

The omnibus F-ratios for the sets of interactive effects of the orthogonal contrasts for cross-cultural sites with childhood Social Vulnerability Cognitive Schemata $(R=.08, p=.17)$, childhood Maternal Sensitivity $(R=.07, p=.35)$, and childhood Resource Instability $(R=.07$, $p=.17$ ) were not statistically significant for adult Slow LH Strategy, suggesting statistical invariance across study sites for the effects of these three predictor variables.

Behavioral Regulation (Cascade Equation 5, $R=.60, p=.00$ )

Also as expected, the main effect of adult Slow LH Strategy, as measured by the Super-K Factor, upon adult Behavioral Regulation was statistically significant and positive $(s R=.47, p=.00)$, and the main effect of childhood Social Vulnerability Cognitive Schemata upon adult Behavioral Regulation was statistically significant and negative ( $s R=-.31, p=.00)$. However, the main effects of childhood Maternal Sensitivity and Resource Instability upon adult Behavioral Regulation were not statistically significant. 
The omnibus F-ratio for the set of main effects of the orthogonal contrasts for crosscultural sites upon adult Behavioral Regulation was statistically significant $(R=.16, p=.00)$. Three contrast main effects were statistically significant, indicating that the baseline level of adult Behavioral Regulation was: $(\mathrm{C} 1)$ lower in the Americas than in Europe $(s R=-.01$, $p=.05)$; (C2) higher in North America than South America $(s R=.12, p=.00)$; and (C4) higher in Sweden than in the United Kingdom $(s R=.06, p=.00)$.

The omnibus F-ratio for the set of interactive effects of the orthogonal contrasts for cross-cultural sites with adult Slow LH Strategy was also statistically significant $(R=.08$, $p=.03$ ). Two interaction terms between the contrasts and adult Slow LH Strategy were found statistically significant, indicating that the predicted effect of adult Slow LH Strategy on adult Behavioral Regulation was: (C1) higher in the Americas than in Europe $(s R=.05, p=.01)$; and (C2 lower in the USA than in Mexico $(s R=.12, p=.03)$. However, these effects were both smaller in absolute magnitude than the main effect of adult Slow LH Strategy so that in neither case were the directions of that main effect reversed, just either somewhat augmented or attenuated.

As with adult Slow LH Strategy, the omnibus F-ratios for the sets of interactive effects of the orthogonal contrasts for cross-cultural sites with childhood Social Vulnerability Cognitive Schemata $(R=.06, p=.34)$, childhood Maternal Sensitivity $(R=.06, p=.45)$, and childhood Resource Instability $(R=.05, p=.57)$ were not statistically significant for adult Behavioral Regulation. This indicates that the effects of these three predictor variables were statistically invariant across study sites.

\section{Dark Inventory of DT Traits (Cascade Equation 6, $R=.69, p=.00$ )}

Also as expected, the main effect of adult Behavioral Regulation upon adult "Dark Triad" Traits was statistically significant and negative $(s R=-.55, p=.00)$, the main effect of adult Slow LH Strategy upon adult "Dark Triad" Traits was statistically significant and 
negative $(s R=-.35, p=.00)$, and the main effect of childhood Social Vulnerability Cognitive Schemata upon adult "Dark Triad" Traits was statistically significant and positive $(s R=.13$, $p=.00)$. However, the residual main effect of childhood Maternal Sensitivity upon adult "Dark Triad" Traits and the residual main effect of childhood Resource Instability upon adult "Dark Triad" Traits were not statistically significant. These two latter were instead transmitted as indirect effects through adult Behavioral Regulation and adult Slow LH Strategy.

The omnibus F-ratio for the set of main effects of the orthogonal contrasts for crosscultural sites upon adult "Dark Triad" Traits was statistically significant $(R=.11, p=.00)$. Two contrast main effects were statistically significant indicating that the baseline level of adult "Dark Triad" Traits was: (C2) lower in North than South America $(s R=-.06, p=.00)$; and $(\mathrm{C} 4)$ lower in Sweden than in the United Kingdom $(s R=-.09, p=.00)$.

Moreover, the omnibus F-ratio for the set of interactive effects of the orthogonal contrasts for cross-cultural sites with adult Slow LH Strategy was statistically significant $(R=.08, p=.02)$. Only one of the interaction terms between the contrasts and adult Slow LH Strategy was found statistically significant: (C4) indicating a higher predicted effect of adult Slow LH Strategy on adult Behavioral Regulation in Sweden than in the United Kingdom $(s R=-.04, p=.01)$. However, this effect was smaller in absolute magnitude than was the main effect of adult Slow LH Strategy, so that the direction of that main effect was not reversed, just either somewhat augmented or attenuated.

Nevertheless, the omnibus F-ratios for the sets of interactive effects of the orthogonal contrasts for cross-cultural sites with adult Behavioral Regulation $(R=.07, p=.06)$, childhood Social Vulnerability Cognitive Schemata $(R=.05, p=.57)$, childhood Maternal Sensitivity $(R=.06, p=.15)$, and childhood Resource Instability $(R=.05, p=.59)$ were not statistically 
significant for adult "Dark Triad" Traits. This indicates that the effects of these three predictor variables were statistically invariant across study sites.

Interpersonal Aggression (Cascade Equation 7, $R=.41, p=.00$ )

Finally, as expected, the main effect of adult "Dark Triad" Traits upon adult Interpersonal Aggression was statistically significant and positive $(s R=.28, p=.00)$, the main effect of adult Behavioral Regulation upon Interpersonal Aggression was statistically significant and negative $(s R=-.18, p=.00)$, and the main effect of childhood Resource Instability upon Interpersonal Aggression was statistically significant and positive $(s R=.08$, $p=.00)$. However, the residual main effects of adult Slow LH Strategy, childhood Social Vulnerability Cognitive Schemata and Maternal Sensitivity upon adult Interpersonal Aggression were not statistically significant. These three latter were instead transmitted as indirect effects through adult "Dark Triad" Traits and adult Behavioral Regulation.

The omnibus F-ratio for the set of main effects of the orthogonal contrasts for crosscultural sites upon adult Interpersonal Aggression was statistically significant $(R=.09, p=.04)$. One contrast main effect was statistically significant: (C2) indicating a higher baseline level of adult Interpersonal Aggression in North than South America $(s R=.06, p=.01)$.

Moreover, the omnibus F-ratio for the set of interactive effects of the orthogonal contrasts for cross-cultural sites with childhood Social Vulnerability Cognitive Schemata was statistically significant $(R=.11, p=.01)$. Only one of the interaction terms between the contrasts and childhood Social Vulnerability Cognitive Schemata was found statistically significant: (C2) indicating a lower predicted effect of childhood Social Vulnerability Cognitive Schemata on adult Interpersonal Aggression in North than in South America ( $s R=-$ $.08, p=.00)$. Although the main effect of childhood Social Vulnerability Cognitive Schemata was not statistically significant, it was nevertheless negative as predicted. 
In addition, the omnibus F-ratio for the set of interactive effects of the orthogonal contrasts for cross-cultural sites with childhood Resource Instability was statistically significant $(R=.10, p=.01)$. Only one of the interaction terms between the contrasts and childhood Resource Instability was found statistically significant: (C2) indicating a higher predicted effect of adult childhood Resource Instability on adult Interpersonal Aggression in North than South America $(s R=.08, p=.00)$. However, this effect was equal in both absolute magnitude and direction to the main effect of childhood Resource Instability so that the direction of that main effect was not reversed, just somewhat augmented in North America and attenuated in South America.

Nevertheless, the omnibus F-ratios for the sets of interactive effects of the orthogonal contrasts for cross-cultural sites with adult "Dark Triad" Traits $(R=.08, p=.11)$, Behavioral Regulation $(R=.05, p=.83)$, adult Slow LH Strategy $(R=.06, p=.49)$, and childhood Maternal Sensitivity $(R=.06, p=.51)$ were not statistically significant for adult Interpersonal Aggression. This indicates that the effects of these three predictor variables were statistically invariant across study sites.

\section{DISCUSSION}

All of the hypothesized structural relations within the a priori specified sequence in the cascade model were supported for the seven major constructs in terms of both the statistical significance and expected direction of effects. All of the seven sets of main effects for the planned orthogonal contrasts representing baseline cross-cultural differences among the study sites were statistically significant, except for their effects upon childhood Maternal Sensitivity, which appeared to be statistically invariant across study sites. The main effects of the specific contrasts were generally small in magnitude, and few of them reached statistically significant levels. Of the twenty-one sets of interactive effects of the planned orthogonal contrasts with each prior criterion variable qua predictor, representing cross- 
cultural differences among the study sites in the effects of each successive predictor, five reached conventional levels of statistical significance. The statistically significant interaction effects of contrasts with predictors were once again relatively few and small in magnitude. In no case was the magnitude and direction of the interactions able to completely reverse that of the corresponding main effect of the predictor, but merely either augmented or attenuated it somewhat across the affected study sites. We can therefore conclude that these results generally support both the configural and metric invariance of the cascade model tested to a relatively high, albeit imperfect, degree.

Although this is a purely correlational analysis, the intent was to evaluate the plausibility of our causal theory. We therefore present the narrative of what we construe to be the developmental sequence that we have tentatively reconstructed and estimated in this study, with the necessary caveat that none of our empirical results can support any definitive causal inferences. To streamline this narrative for the purpose of exposition, we will temporarily suspend all qualifiers to that effect, as well as ignore the various small but statistically significant cross-cultural differences identified.

\section{Summary of Results}

First, resource instability during childhood reduces perceived maternal sensitivity during childhood. Second, perceived maternal sensitivity during childhood inhibits the development of early social vulnerability cognitive schemata, whereas resource instability during childhood promotes them. Third, early social vulnerability cognitive schemata inhibit the development of adult slow LH strategy, as does resource instability during childhood, whereas maternal sensitivity during childhood promotes it. Fourth, adult slow LH strategy increases behavioral regulation, whereas early social vulnerability cognitive schemata decrease it. Fifth, behavioral regulation inhibits the development of adult "Dark" personality traits, as does adult slow LH strategy, whereas early social vulnerability cognitive schemata 
promote them. Sixth, and finally, adult "Dark" personality traits promote interpersonal aggression, as does resource instability during childhood, whereas enhanced behavioral regulation inhibits it.

Figure 2 illustrates these relations graphically. Note that the magnitudes of the links between immediately adjacent constructs in the diagram are generally stronger than those between constructs that are not immediately adjacent to each other. This pattern provides a certain degree of empirical support for our theoretical ordering of the variables in the hypothesized sequence.

[Insert Figure 2 Here]

\section{Limitations of the Study}

The present study was based entirely on retrospective self-reports by research participants via convenience, not representative, sampling. The reconstructed temporal sequence of developmental events is therefore based on the sequence among the referents of these self-reports, or the relative timing of the things being retrospectively described. The hypothesized causal sequence is, therefore, based on theoretical considerations rather than being the results of a true longitudinal study, where each event was measured as it actually occurred over the participant's lifetime. Possibly, the memories on which these retrospective reports are based might be at least partially reconstructed based on subsequent experiences. Alternatively, a true longitudinal study of the latter type would take at least two decades to complete, and would be a monumental undertaking to coordinate among five international sampling locations. The present study is thus our best attempt to do what we could to develop a theoretically plausible model of development for these important psychological constructs given the currently available resources.

Our cascade model contains seven equations, one predicting each criterion variable of interest, and the order among these criterion variables was theoretically specified based on 
LH theory. Consequently, it should be noted that the generation of plausible alternative hypotheses regarding the causal order that we specified among criterion variables is always possible. Specifically, the number of permutations that it is mathematically possible to generate among our seven criterion variables is seven factorial (usually denoted $7 !$ ), which is equal to no less than 5040 permutations. That means that there are 5040 mathematically possible orders among our seven equations. It is therefore self-evident that testing all such mathematically possible permutations is statistically indefensible, given the massive capitalization on chance that would no doubt occur both in hypothesis testing and parameter estimation.

That being said, there are some plausible rival hypotheses that might be substantively reasonable and perhaps scientifically productive to review. Among these is the relation between childhood resource instability and perceived maternal sensitivity during childhood. This is a special case of the more general observation that developmental research often suffers from the problem of genetic confounding of effects that are commonly attributed to the environment (Plomin, DeFries, Knopik, \& Neiderhiser, 2016). The majority of individuals are raised by their own biological parents, to whom they are closely genetically related. Putatively "environmental" constructs, such as our measure of resource instability during childhood, are inevitably influenced by parental behaviors. To the extent that such parental behaviors may be partially heritable, the resulting childhood environments may be influenced by genes that are also present in their offspring (Rowe, 1994). This creates geneenvironment correlations that necessarily confound any predictions of future offspring behavioral outcomes (Buss, 1987). For instance, early adversity predicting future offspring outcomes may be at least partially attributable to statistically spurious effects of common genetic influences throughout development. Maternal genes that might be influencing perceived maternal sensitivity (if accurate) could also be exerting pleiotropic behavioral 
effects on the generation of household resource instability during childhood (see chapter on Evolutionary Ecological Systems Theory; Hertler, Figueredo, Peñaherrera Aguirre, Fernandes, \& Woodley of Menie, 2018). If this were indeed occurring, then the direction of the effect from resource instability to maternal sensitivity in our model would need to be reversed. Although the current model is based on the predictions of LH theory, work is currently underway to address this important question using behavioral-genetic methods on genetically informative data (Figueredo, Cabeza de Baca, \& Richardson, 2020).

Another such equivocal relation is that between behavioral regulation and the development of adult "Dark" personality traits. The association among these constructs is well known, and deficits in behavioral regulation (e.g., "impulsiveness" as opposed to "selfcontrol") are often included in the very definition of some "Dark" personality traits, such as Psychopathy. The causal ordering among these traits, however, remains uncertain. Some recent models, such as the one presently reported, have hypothesized that the enhanced levels of executive functioning associated with slower LH strategy (e.g., Figueredo, Cuthbertson, Kauffman, Weil, \& Gladden, 2012; Salmon, Figueredo, \& Woodburn, 2009) suppresses the development of psychopathic and aggressive attitudes (Figueredo, Jacobs, Gladden, Bianchi, Patch, Beck, Kavanagh, Sotomayor-Peterson, Jiang, \& Li, 2018); another recent model, however, specifies "Dark" personality traits as instead causally prior to deficits in executive functions (Figueredo, Patch, Perez-Ramos, \& Cruz, 2018). Both models were cross-culturally replicated, both explain a substantial amount of variance in interpersonal aggression $\left(R^{2}=.76\right.$ and $R^{2=} .52$, respectively), and both propose plausible mechanisms for their preferred directionalities. It is therefore not possible at this stage of the ongoing research program to state definitively which constructs precede the others during development, and reversing the direction of prediction has had minimal impact upon the performance of such models. 
Finally, it might be worthwhile to mention that all the events reported by respondents in this study presumably transpired in modern environments, within either developed or developing countries, which may or may not closely reflect the more distant ancestral environments of these same societies. Our evolutionary-developmental model is based on the assumption that the developmental mechanisms expressed in such modern environments presumably evolved in more ancestral environments, and that the selective pressures shaping such mechanisms were reasonably comparable then and now (see the concept of Adaptively Relevant Environments; Figueredo, Brumbach, Jones, Sefcek, Vásquez, \& Jacobs, 2007; Irons, 1998). However, we have no way to ascertain at present whether or to what extent that assumption might be warranted. This is an important problem which must await further research to better elucidate.

\section{Evolutionary Significance of the Study}

It is the general consensus within both health and developmental psychology that the development of well-being, self-esteem, secure attachment, and cooperative supportive patterns of social relation in adulthood is largely a consequence of supportive parental care, as through affectionate touch, lack of corporal punishment, responsiveness to the child's needs, play activities, and social embeddedness (Sanders, 2003; Wolff \& Van Ijzendoorn, 1997). However, we see this as a partial and incomplete account of diversity in human fitness landscapes, as there is no single way of optimizing adaptation. Whereas the above concerted set of developmental conditions certainly permits what we consider healthy psychological development, alternative developmental conditions leading to other psychosocial traits can also be adaptive from the perspective of evolutionary success and therefore their intergenerational maintenance, in spite of not being "healthy" from the point of view of modern cultural standards (Hertler, Figueredo, Peñaherrera-Aguirre, Fernandes, \& Woodley of Menie, 2018). Individuals and communities may thus create and reinforce social niches 
where seemingly chaotic syndromes of behavior are adaptively functional in the context of fast LH strategies. We argue that the self-reinforcing nature of LH strategies and their psychosocial sequelae happens partially through active niche construction.

Niche construction is the process by which organisms modify their own and each other's niches through their own activities, generating new conditions for development, and a new context for adaptation. Although the focus of niche construction theory has been primarily at the ecological modifications and ecological consequences to organisms (Flack, Girvan, De Waal, \& Krakauer, 2006), the logic of active niche construction can also be applied to psychosocial modifications and implications drawn for psychosocial consequences. Populations and their subgroups, such as families and individuals, can also be analyzed through the lens of niche construction theory, as they modify and are impacted by modifications to their micro-niches. This means that the developmental niches constructed for offspring throughout evolutionary history are not all the same: Different forms of social relationship may have been fostered for different communities or families within them, depending on their ecological conditions and personal characteristics.

It is readily recognized that the contended "optimal" developmental niche is constructed, as it does not come exclusively from the external environment but from social organization (Narvaez, Wang, \& Cheng, 2016; Sterelny, 2007). Likewise, alternative developmental niches are constructed and not simply a product of the external environment to which groups and individuals are subjected. However, the term "construction" should not necessarily connote the meaning of premeditated intentionality: Niche construction is often a selected response to conditions in the environment and limited to the current behavioral repertory of the individuals constructing the niche. Accordingly, comparatively faster LH communities would construct niches that not only suit but actually reinforce their biopsychosocial adaptations, optimizing their fitness by building cultural practices that 
capitalize on the high variability of conditions. Instability and adversity themselves are reliable constants in their ecology, and such communities would benefit, from the point of view of evolutionary success, from the ability to navigate such environments rather than avoid them and prioritize traits considered "optimal" from the point of view of health psychology.

Thus, the family environment may serve to prepare the child for the average social environment that recurrently occurs in the family's preceding history. An adaptive family environment does not prepare children for an idealized future environment, but rather to conditions close to their present reality. Many niches are stable, especially for those with a largely stable culture, where reliable sociocultural conditions exist. The notion that constructed niches protect against harshness and encourage safety and social cohesion is common (Flynn, Laland, Kendal, \& Kendal, 2013). The maintenance of such long-term social features is prioritized by individuals and groups that live in relatively stable, predictable niches in which cumulative and future payoffs to current investments are reliable. For example, interpersonal aggression is frequently interpreted as a manifestation of failed impulse control or an underlying psychopathological condition, and thus, seen as maladaptive (for a review, see Fernandes, Figueredo, \& Peñaherrera-Aguirre, 2017). Aggression indeed jeopardizes the successful implementation of long-term mating strategies, investments in kin, and the maintenance of long-term cooperative efforts, thus reducing or impeding group cohesion (Figueredo \& Jacobs, 2010).

Other niches, however, involve largely unstable conditions (Rowley-Conwy \& Layton, 2011). Parenting styles that foster stability may seem ideal from the point of view of production of subjective well-being, but out of sync with the reality of the adult ecology that awaits individuals. In unstable, faster LH communities, interventions on aggression without simultaneous interventions on providing stable and predictable opportunities are likely to 
produce mismatch, dissonance, and the deprivation of adaptive strategies to solve problems faced in one's niche (Ellis et al. 2012). Modifying rough parenting styles that train children to face and succeed in adversity may not need to be discarded as a goal, but to ensure long-term adjustment one should arguably also correspondingly modify the social niche that these children will encounter as adults (Brumbach, Figueredo, \& Ellis, 2009; Ellis et al., 2009, 2012). For example, reactivity and irritability early in life can be a valuable basis for assertiveness and status-seeking in adulthood and parenting styles may train children for that, whereas in other social niches such early traits may be detrimental to successfully navigating adult relations (Worthman \& Brown, 2005).

The fact that multiple forms of child abuse, neglect, lack of sensitivity, and adversity in parenting styles in general are intergenerationally cyclical is well known (Belsky, 1993; Kaufman \& Ziegler, 1989), and the present cascade analysis reinforces that notion. Indeed, a recent longitudinal cross-national study has used critical dimensions such as household chaos, neighborhood danger, harsh maternal parenting, and maternal affection to predict child outcomes such as externalizing behaviors, internalizing behaviors, and school achievement (Deater-Deckard et al., 2019). The cross-cultural invariance of these results across low- and middle- income countries (LMICs) were confirmed by multigroup structural equation models (MSEMs). However, to our knowledge this is the first study to explicitly tie this phenomenon empirically to the nexus of LH speed, permitting a theoretical analysis of the adaptive aspects behind it. Facilitating intergenerational recurrence is the self-reinforcing nature of LH strategies (Pianka, 1970), occurring where the majority of others in the social niche are also pursuing fast LH and short-term social strategies (rather than favoring or even permitting long-term bond formation). This collective self-reinforcement of LH strategies permits the establishment of community effort in niche construction. What is forwarded here is the hypothesis that chaotic patterns of relationship in childhood prepare for the equally chaotic 
unpredictable and harsh niches of fast LH adulthood. The psychobehavioral set of characteristics described in the above cascade are not necessarily maladaptive from the point of view of successful replication across generations, and therefore, appear evolutionary functional. They only appear maladjusted to the expectations of someone who is not embedded in fast LH niches.

Furthermore, rather than being premeditated, intentional, or even ego-syntonic, the intergenerational repetition of these parenting practices may be perceived as undesirable even by those who practice them. This realization serves to avoid blaming individuals but also to understand that parenting practices may be perceived at least partly as unavoidable and uncontrollable, which reinforces the theoretical notion that it is a product of the niche. Second, no relationship between childhood experiences and adult patterns of behavior identified in the present study or in previous studies is deterministic. In the face of measurement error and stochastic processes, individuals do sometimes break out of the pattern of intergenerational repetition. As such, it is in no way implied by the present discussion that it is the inevitable fate of individuals to reproduce the parenting and familial patterns of relationship to which they were exposed during earlier stages of development.

\section{References}

Beitchman, J.H., Zai, C.C., Muir, K., Berall, L., Nowrouzi, B., Choi, E., \& Kennedy, J.L. (2012). Childhood aggression, callous-unemotional traits and oxytocin genes. European child \& adolescent psychiatry, 21, 125-132.

Belsky, J. (1993). Etiology of child maltreatment: A developmental ecological analysis. Psychological Bulletin, 114, 413-434.

Belsky, J., Schlomer, G.L., \& Ellis, B.J. (2012). Beyond cumulative risk: distinguishing harshness and unpredictability as determinants of parenting and early life history strategy. Developmental Psychology, 48, 662- 673. 
Black, C.J., Figueredo, A.J., \& Jacobs, W.J. (2017). Substance, history, and politics: An examination of the conceptual underpinnings of alternative approaches to the life history narrative. Evolutionary Psychology, 15, 1474704916670402.

Black, C.J., Figueredo, A.J., \& Jacobs, W.J. (2018). Life history theory. In V. Zeigler-Hill, T. K. Shackelford (Eds.), Encyclopedia of Personality and Individual Differences, https://doi.org/10.1007/978-3-319-28099-8 1542-2

Black, C.J., Patch, E.A., Figueredo, A.J., \& Jacobs, W.J. (under revision). Shared roles: Child and adolescent events and their perceptions influence developmental timing and health outcomes.

Black, C.J., \& Gable, J.C. (2012). Early Environment Questionnaire. Retrieved from http://www.u.arizona.edu/ cjblack/EEQ.html

Blair, R.J.R. (2003). Neurobiological basis of psychopathy. The British Journal of Psychiatry, 182, 5-7.

Book, A.S., \& Quinsey, V.L. (2004). Psychopaths: cheaters or warrior-hawks? Personality and Individual Differences, 36, 33-45.

Brislin, R.W. (1970). Back-translation for cross-cultural research. Journal of cross-cultural psychology, 1, 185-216.

Brumbach, B.H., Figueredo, A.J., \& Ellis, B.J. (2009). Effects of harsh and unpredictable environments in adolescence on development of life history strategies: A longitudinal test of an evolutionary model. Human Nature, 20, 25-51.

Buss, D.M. (1987). Selection, evocation, and manipulation. Journal of Personality and Social Psychology, 53, 1214-1221.

Cabeza de Baca, T., \& Ellis, B.J. (2017). Early Stress, parental motivation, and reproductive decision-making: Applications of life history theory to parental behavior. Current Opinion in Psychology, 15, 1-6. DOI: 10.1016/j.copsyc.2017.02.005 
Cabeza de Baca, T., Figueredo, A.J., \& Ellis, B.J. (2012). An evolutionary analysis of variation in parental effort: Determinants and assessment. Parenting: Science and Practice, Special Issue: The Arc of Parenting from Epigenomes to Ethics, 12, 94-104.

Cabeza de Baca, T., Sotomayor-Peterson, M., Smith-Castro, V., \& Figueredo, A.J. (2014). Contributions of matrilineal and patrilineal kin alloparental effort to the development of life history strategies and patriarchal values: A cross-cultural life history approach. Journal of Cross-Cultural Psychology, 45, 534-554.

Cabeza de Baca, T., Sotomayor-Peterson, M., \& Figueredo, A.J. (2017). Parental Investment and Parenting. In T. K. Shackelford \& Weekes-Shackelford, V. (Eds.), Encyclopedia of evolutionary psychological science. Cham, Switzerland: Springer. DOI:10.1007/978-3-319-16999-6_3813-1

Cabeza de Baca, T., Wahl, R.A., Barnett, M.A., Figueredo, A.J., \& Ellis, B.J. (2016). Adversity, Adaptive Calibration, and Health: The case of disadvantaged families. Adaptive Human Behavior and Physiology, 2, 93-115. DOI: 10.1007/s40750-016$0042-\mathrm{z}$

Cohen, J., \& Cohen, P. (1983). Applied Multiple Regression/Correlation Analysis for the Behavioral Sciences. Hillsdale, NJ: Erlbaum.

Croston, R., Branch, C.L., Kozlovsky, D.Y., Dukas, R., \& Pravosudov, V.V. (2015). Heritability and the evolution of cognitive traits. Behavioral Ecology, 26, 1447-1459. Dadds, M.R., Allen, J.L., Oliver, B.R., Faulkner, N., Legge, K., Moul, C., ... \& Scott, S. (2012). Love, eye contact and the developmental origins of empathy $\mathrm{v}$. psychopathy. The British Journal of Psychiatry, 200, 191-196.

Dadds, M.R., Moul, C., Cauchi, A., Dobson-Stone, C., Hawes, D.J., Brennan, J., \& Ebstein, R.E. (2013). Methylation of the oxytocin receptor gene and oxytocin blood levels in the development of psychopathy. Development and psychopathology, 26, 33-40. 
Davis, M.F., Guggenheim, C., Figueredo, A.J., Wright, A., \& Locke, C. (2007). Differential parental investment in Tucson babies. Journal of the Arizona Nevada Academy of Science, 39, 65-72.

Deater-Deckard, K., Godwin, J., Lansford, J. E., Tirado, L. M. U., Yotanyamaneewong, S., Alampay, L. P., ... \& Di Giunta, L. (2019). Chaos, danger, and maternal parenting in families: Links with adolescent adjustment in low- and middle-income countries. Developmental science, 22(5), e12855.

Demetriou, A., Christou, C., Spanoudis, G., \& Platsidou, M. (2002). The development of mental processing: Efficiency, working memory, and thinking. Monographs of the Society of Research in Child Development 67(1, Serial No. 268):1-154.

Ellis, B.J., Del Giudice, M., Dishion, T.J., Figueredo, A.J., Gray, P., Griskevicius, V., ... \& Wilson, D.S. (2012). The evolutionary basis of risky adolescent behavior: implications for science, policy, and practice. Developmental psychology, 48, 598.

Ellis, B.J., Figueredo, A.J., Brumbach, B.H., \& Schlomer, G.L. (2009). Fundamental dimensions of environmental risk: The impact of harsh versus unpredictable environments on the evolution and development of life history strategies. Human Nature, 20, 204-268.

Figueredo, A.J., Brumbach, B.H., Jones, D.N., Sefcek, J.A., Vásquez, G., \& Jacobs, W.J. (2007). Ecological constraints on mating tactics. In Geher, G., \& Miller, G.F., (Eds.), Mating Intelligence: Sex, Relationships and the Mind's Reproductive System (pp. 335361). Mahwah, NJ: Lawrence Erlbaum.

Figueredo, A.J., Cabeza de Baca, T., \& Richardson, G.B. (2020). Hybrid behavior-genetic models of the confounding gene-environment correlations in the development of life history strategy: Two convergent approaches. Journal of the Methods and Measurement in the Social Sciences, manuscript submitted for publication. 
Figueredo, A.J., Cuthbertson, A.M., Kauffman, I.A., Weil, E., \& Gladden, P.R. (2012). The interplay of behavioral dispositions and cognitive abilities: Sociosexual orientation, emotional intelligence, executive functions, and life history strategy. Temas em Psicologia, 20(1), 81-100.

Figueredo, A.J., Gladden, P.R., Sisco, M.M., Patch, E.A., \& Jones, D.N. (2015). The unholy trinity: The Dark Triad, sexual coercion, and Brunswik-symmetry. Evolutionary Psychology, 13, 147470491501300208.

Figueredo, A.J., \& Gorsuch, R. (2007). Assortative mating in the Jewel wasp: 2. Sequential canonical analysis as an exploratory form of path analysis. Journal of the Arizona Nevada Academy of Science, 39, 59-64.

Figueredo, A.J., \& Jacobs, W.J. (2010). Aggression, risk-taking, and alternative life history strategies: The behavioral ecology of social deviance. In M. Frias-Armenta \& V. Corral-Verdugo (Eds.), Biopsychosocial perspectives on aggression (pp. 3-28). Hauppauge: Nova Science Publishers.

Figueredo, A. J., Jacobs, W. J., Gladden, P. R., Bianchi, J., Patch, E. A., Kavanagh, P. S., ... \& Li, N. P. (2018). Intimate partner violence, interpersonal aggression, and life history strategy. Evolutionary Behavioral Sciences, 12, 1-13.

Figueredo, A.J., McKnight, P.E., McKnight, K.M., \& Sidani, S. (2000). Multivariate modeling of missing data within and across assessment waves. Addiction, 95(11s3), 361-380. doi: 10.1046/j.1360-0443.95.11s3.6.x

Figueredo, A.J., Patch, E.A., \& Ceballos, C.E.G. (2015). A life history approach to the dynamics of social selection. In V. Zeigler-Hill, L. L. M. Welling, \& T. K. Shackelford (Eds.). Evolutionary perspectives on social psychology (pp. 363-372). New York, NY: Springer. 
Figueredo, A.J., Patch, E.A., Perez-Ramos, M., \& Cruz, G.J. (2018). Evolutionary Influences on Aggressive Behaviour. In A. Vazsonyi, D. Flannery, \& M. Delisi (eds.), Cambridge handbook of violent behaviour and aggression (pp. 65-81). Cambridge, MA: Cambridge University Press. DOI: 10.1017/ 9781316847992

Figueredo, A.J., \& Rushton, J.P. (2009). Evidence for shared genetic dominance between the general factor of personality, mental and physical health, and life history traits. Twin Research and Human Genetics, 12, 555-563.

Figueredo, A.J., Vásquez, G., Brumbach, B.H., \& Schneider, S.M.R. (2004). The heritability of life history strategy: The K-factor, covitality, and personality. Social Biology, 51, 121-143.

Figueredo, A.J., Vásquez, G., Brumbach, B.H., \& Schneider, S.M.R. (2007). The K-factor, covitality, and personality: A psychometric test of life history theory. Human Nature, $18,47-73$.

Figueredo, A.J., Vásquez, G., Brumbach, B.H., Schneider, S.M.R., Sefcek, J.A., Tal, I.R., Hill, D., Wenner, C.J., \& Jacobs, W.J. (2006). Consilience and life history theory: From genes to brain to reproductive strategy. Developmental Review, 26, 243-275.

Flack, J.C., Girvan, M., De Waal, F.B., \& Krakauer, D.C. (2006). Policing stabilizes construction of social niches in primates. Nature, 439, 426-429.

Flynn, E.G., Laland, K.N., Kendal, R.L., \& Kendal, J.R. (2013). Target article with commentaries: Developmental niche construction. Developmental Science, 16, 296313.

Gioia, G.A., Isquith, P.K., Retzlaff, P.D., \& Espy, K.A. (2002). Confirmatory factor analysis of the Behavior Rating Inventory of Executive Function (BRIEF) in a clinical sample. Child Neuropsychology, 8, 249-257. doi: 10.1076/chin.8.4.249.13513

Gorsuch, R.L. (1983). Factor analysis (2nd ed.). Hillsdale, N.J.: L. Erlbaum Associates. 
Gorsuch, R.L. (2016). UniMult: For univariate and multivariate data analysis. Altadena, CA: UniMult, Inc. Retrieved from https://unimult.000webhostapp.com/

Gosling, S.D., Rentfrow, P.J., \& Swann, W.B., Jr. (2003). A Very Brief Measure of the Big Five Personality Domains. Journal of Research in Personality, 37, 504-528.

Griskevicius, V., Ackerman, J.M., Cantú, S.M., Delton, A.W., Robertson, T.E., Simpson, J.A., ... \& Tybur, J.M. (2013). When the economy falters, do people spend or save? Responses to resource scarcity depend on childhood environments. Psychological science, 24, 197-205.

Griskevicius, V., Tybur, J.M., Delton, A.W., \& Robertson, T.E. (2011). The influence of mortality and socioeconomic status on risk and delayed rewards: a life history theory approach. Journal of personality and social psychology, 100(6), 1015.

Guggenheim, C.B., Davis, M.F., \& Figueredo, A.J. (2007). Sons or daughters: A crosscultural study of sex-ratio biasing and differential parental investment. Journal of the Arizona Nevada Academy of Science, 39(2), 73-90.

Hackman, D.A., Farah, M.J., \& Meaney, M.J. (2010). Socioeconomic status and the brain: Mechanistic insights from human and animal research. Nature Reviews Neuroscience, 11, 651-659. http://dx.doi.org/ 10.1038/nrn2897

Hertler, S.C., Figueredo, A.J., Peñaherrera-Aguirre, M., \& Fernandes, H.B.F, \& Woodley of Menie, M. A. (2018). Life history evolution: A biological meta-theory for the social sciences. New York, NY: Palgrave Macmillan. ISBN: 978-3-319-90125-1.

Heym, N., Firth, J., Kibowski, F., Sumich, A., Egan, V. \& Bloxsom, C.A.J. (2019). Empathy at the heart of darkness: empathy deficits that bind the dark triad and those that mediate indirect relational aggression. Frontiers in Psychiatry, 10, 95. 
Hill, S.E., Prokosch, M.L., DelPriore, D.J., Griskevicius, V., \& Kramer, A. (2016). Low childhood socioeconomic status promotes eating in the absence of energy need. Psychological Science, 27, 354-364.

Jonason, P.K., Icho, A., \& Ireland, K. (2016). Resources, harshness, and unpredictability: the socioeconomic conditions associated with the Dark Triad traits. Evolutionary Psychology, 14, 1-11.

Jonason, P.K., Li, N.P., Webster, G.D., \& Schmitt, D.P. (2009). The dark triad: Facilitating a short-term mating strategy in men. European Journal of Personality: Published for the European Association of Personality Psychology, 23, 5-18.

Jones, D.N., \& Figueredo, A.J. (2013). The core of darkness: Uncovering the heart of the Dark Triad. European Journal of Personality, 27, 521-531.

Jones, D.N., \& Paulhus, D.L. (2011). Differentiating the Dark Triad within the interpersonal circumplex. In L.M. Horowitz \& S. Strack (Eds.), Handbook of interpersonal psychology (pp. 249-269). New York: Guilford.

Kaufman, J., \& Zigler, E. (1989). The intergenerational transmission of child abuse. In D. Cicchetti \& V. Carlson (Eds.), Child maltreatment: Theory and research on the causes and consequences of child abuse and neglect (pp. 129-150). Cambridge, MA: Cambridge University Press.

Keller, P.S., Blincoe, S., Gilbert, L.R., Dewall, C.N., Haak, E.A., \& Widiger, T. (2014). Narcissism in romantic relationships: A dyadic perspective. Journal of Social and Clinical Psychology, 33, 25-50.

Kiehl, K.A. (2006). A cognitive neuroscience perspective on psychopathy: evidence for paralimbic system dysfunction. Psychiatry research, 142, 107-128.

Millon, T., Simonsen, E., Birket-Smith, M., \& Davis, R.D. (Eds.). (2002). Psychopathy: Antisocial, criminal, and violent behavior. Guilford Press. 
Mittal, C., \& Griskevicius, V. (2014). Sense of control under uncertainty depends on people's childhood environment: A life history theory approach. Journal of Personality and Social Psychology, 107(4), 621.

Mouyi, A., (2006). Untangling the cognitive processes web. Paper. Seventh Annual Conference of the International Society for Intelligence Research, San Francisco, California.

Narvaez, D., Wang, L., \& Cheng, Y. (2016). The evolved developmental niche in childhood: Relation to adult psychopathology and morality. Applied Developmental Science, 20, 294-309.

Paulhus, D.L., \& Williams, K. (2002). The Dark Triad of personality: Narcissism, Machiavellianism, and psychopathy. Journal of Research in Personality, 36, 556-568.

Patch, E.A., \& Figueredo, A.J. (2017). Childhood stress, life history, psychopathy, and sociosexuality. Personality and Individual Differences, 115, 108-113.

Pianka, E.R. (1970). On r- and K-selection. American Naturalist, 104, 592-596.

Plomin, R., DeFries, J.C., Knopik, V.S., \& Neiderhiser, J.M. (2016). Top 10 replicated findings from behavioral genetics. Perspectives on Psychological Science, 11, 3-23.

Rowe, D.C. (1994). The limits of family influence. New York: The Guilford Press.

Salmon, C., Figueredo, A.J., \& Woodburn, L. (2009). Life history strategy and disordered eating behavior. Evolutionary Psychology, 7(4), 585-600.

Sanders, M.R. (2003). Triple P-Positive Parenting Program: A population approach to promoting competent parenting. Australian e-journal for the Advancement of Mental Health, 2, 127-143.

Schmitt, D.P., Alcalay, L., Alves, I.C.B., Anderson, C.A., Angelini, A.L., Asendorpf, J.B., ... Zupančič, A. (2017). Narcissism and the strategic pursuit of short-term mating: 
Universal links across 11 world regions of the international sexuality description project-2. Psychological Topics, 26, 89-137.

Sotomayor-Peterson, M., Cabeza de Baca, T., Figueredo, A.J., \& Smith-Castro, V. (2012). Shared parenting, parental effort, and life history strategy: A cross-cultural comparison. Journal of Cross-Cultural Psychology, 44, 620-639.

SAS Institute Inc. (2004). Base SAS 9.1 Procedures guide. Cary, NC: Author.

Sterelny, K. (2007). Social intelligence, human intelligence and niche construction. Philosophical Transactions of the Royal Society B: Biological Sciences, 362(1480), 719-730.

Viding, E., Blair, R.J.R., Moffitt, T.E., \& Plomin, R. (2005). Evidence for substantial genetic risk for psychopathy in 7-year-olds. Journal of Child Psychology and Psychiatry, 46, $592-597$.

Viding, E., McCrory, E., \& Seara-Cardoso, A. (2014). Psychopathy. Current Biology, 24, R871-R874.

Ware, J.E., \& Sherbourne, C.D. (1992). The MOS 36-item short-form health survey (SF-36): I. Conceptual framework and item selection. Medical Care, 30, 473-483.

De Wolff, M.S., \& Van Ijzendoorn, M. H. (1997). Sensitivity and attachment: A meta- analysis on parental antecedents of infant attachment. Child development, 68 , $571-591$.

Worthman, C.M., \& Brown, R.A. (2005). A biocultural life history approach to the developmental psychobiology of male aggression. In D. M. Stoff \& E. J. Susman (Eds.), Developmental psychobiology of aggression (pp. 187-224). Cambridge, UK: Cambridge University Press. 
Young, J.E. (1999). Practitioner's resource series. Cognitive therapy for personality disorders: A schema-focused approach (3rd ed.). Sarasota, FL, US: Professional Resource Press/Professional Resource Exchange.

Young, J. E., \& Brown, G. K. (1999). Young Schema Questionnaires: Short Version. New York: Cognitive Therapy Center of New York. 
Running Head: THE CASCADE OF CHAOS

Table 1

Demographics across 5 cross-cultural sites

\begin{tabular}{lrrrrr}
\hline & Brazil & Mexico & Sweden & UK & US \\
\hline$N$ & 1091 & 118 & 135 & 260 & 144 \\
Age $(M)$ & 32.8 & 21.3 & 25.7 & 19.6 & 18.9 \\
Age $(S D)$ & 10.6 & 2.11 & 5.1 & 2.5 & 1.85 \\
Age Range & $18-74$ & $18-32$ & $19-27$ & $18-45$ & $18-31$ \\
Female $n$ & $757(69 \%)$ & $93(78 \%)$ & $85(57 \%)$ & $233(86 \%)$ & $99(69 \%)$ \\
Male $n$ & $333(31 \%)$ & $25(22 \%)$ & $51(34 \%)$ & $27(14 \%)$ & $44(31 \%)$ \\
\hline
\end{tabular}


Table 2

Cronbach's alphas and part-whole correlations (unit-weighted factor loadings) for the indicators of Childhood Resource Instability (RESINSTAB), Childhood Maternal Sensitivity (MATSEN), Young Schema Questionnaire (YSQ), Slow LH Strategy Factor (SUPER-K), Behavioral Regulation Scales of the BRIEF-A (BEHREG), Dark Inventory Short Form for “Dark Triad” Traits (DI-SF), Same-Sex Interpersonal Relations Ratings Scale (IRRS-S), Opposite-Sex Interpersonal Relations Ratings Scale (IRRS-O), and General Interpersonal Aggression (IPA)

\begin{tabular}{|c|c|c|}
\hline & Alpha & Unit-Weighted Factor \\
\hline \multicolumn{3}{|c|}{ Childhood Resource Instability(RESINSTAB) } \\
\hline HARSH-CHILD & .745 & $0.916^{*}$ \\
\hline INSTA-CHILD & .732 & $0.916^{*}$ \\
\hline \multicolumn{3}{|c|}{ Childhood Maternal Sensitivity(MATSEN) } \\
\hline MATSEN-CHILD & .816 & 1.000 \\
\hline \multicolumn{3}{|c|}{ Social Vulnerability Schemata - Young Schema Questionnaire (YSQ) } \\
\hline$Y S Q-C H I L D A B$ & .910 & $0.802 *$ \\
\hline$Y S Q-C H I L D M A$ & .907 & $0.856^{*}$ \\
\hline$Y S Q-C H I L D V H$ & .848 & $0.856^{*}$ \\
\hline \multicolumn{3}{|c|}{ Young Adult Slow Life History Strategy Factor (SUPER-K) } \\
\hline K-FACTOR & .802 & $0.729 *$ \\
\hline COVITALITY & .846 & $0.730 *$ \\
\hline PERSONALITY & .626 & $0.819^{*}$ \\
\hline \multicolumn{3}{|c|}{ Behavioral Regulation Scales of the BRIEF-A (BEHREG) } \\
\hline EMOTIONAL CONTROL & .932 & $0.881 *$ \\
\hline INHIBIT & .815 & $0.909 *$ \\
\hline SELF MONITOR & .863 & $0.898^{*}$ \\
\hline SHIFT & .817 & $0.892 *$ \\
\hline \multicolumn{3}{|c|}{ Dark Inventory - Short Form (DI-SF) } \\
\hline ANTAGONISTIC & .759 & $0.787 *$ \\
\hline MUTUALISTIC & .557 & $-0.712 *$ \\
\hline LABILITY & .598 & $0.746^{*}$ \\
\hline \multicolumn{3}{|c|}{ Same-Sex Interpersonal Relations Ratings Scale (IRRS-S) } \\
\hline SAME-SEX CONTROL & .893 & $0.922 *$ \\
\hline SAME-SEX PSYCHO & .835 & $0.742 *$ \\
\hline SAME-SEX PHYSICAL & .879 & $0.917^{*}$ \\
\hline SAME-SEX ESCALATED & .977 & $0.920 *$ \\
\hline SAME-SEX SEXUAL & .936 & $0.919 *$ \\
\hline \multicolumn{3}{|c|}{ Opposite Sex Interpersonal Relations Ratings Scale (IRRS-O) } \\
\hline OPPOSITE SEX CONTROL & .876 & $0.905^{*}$ \\
\hline OPPOSITE SEX PSYCHO & .832 & $0.754^{*}$ \\
\hline OPPOSITE SEX PHYSICAL & .879 & $0.894 *$ \\
\hline
\end{tabular}




\begin{tabular}{lcc} 
OPPOSITE SEX ESCALATED & .973 & $0.904^{*}$ \\
OPPOSITE SEX SEXUAL & .898 & $0.903^{*}$ \\
\hline General Interpersonal Aggression (IPA) & & \\
\hline SAME-SEX IRRS & .974 & $0.987^{*}$ \\
OPPOSITE SEX IRRS & .967 & $0.987^{*}$ \\
\hline$* p<.05$ & &
\end{tabular}


Figure 1

The multiple-mediation cascade model hypothesized, showing the sequence of successive stages of development

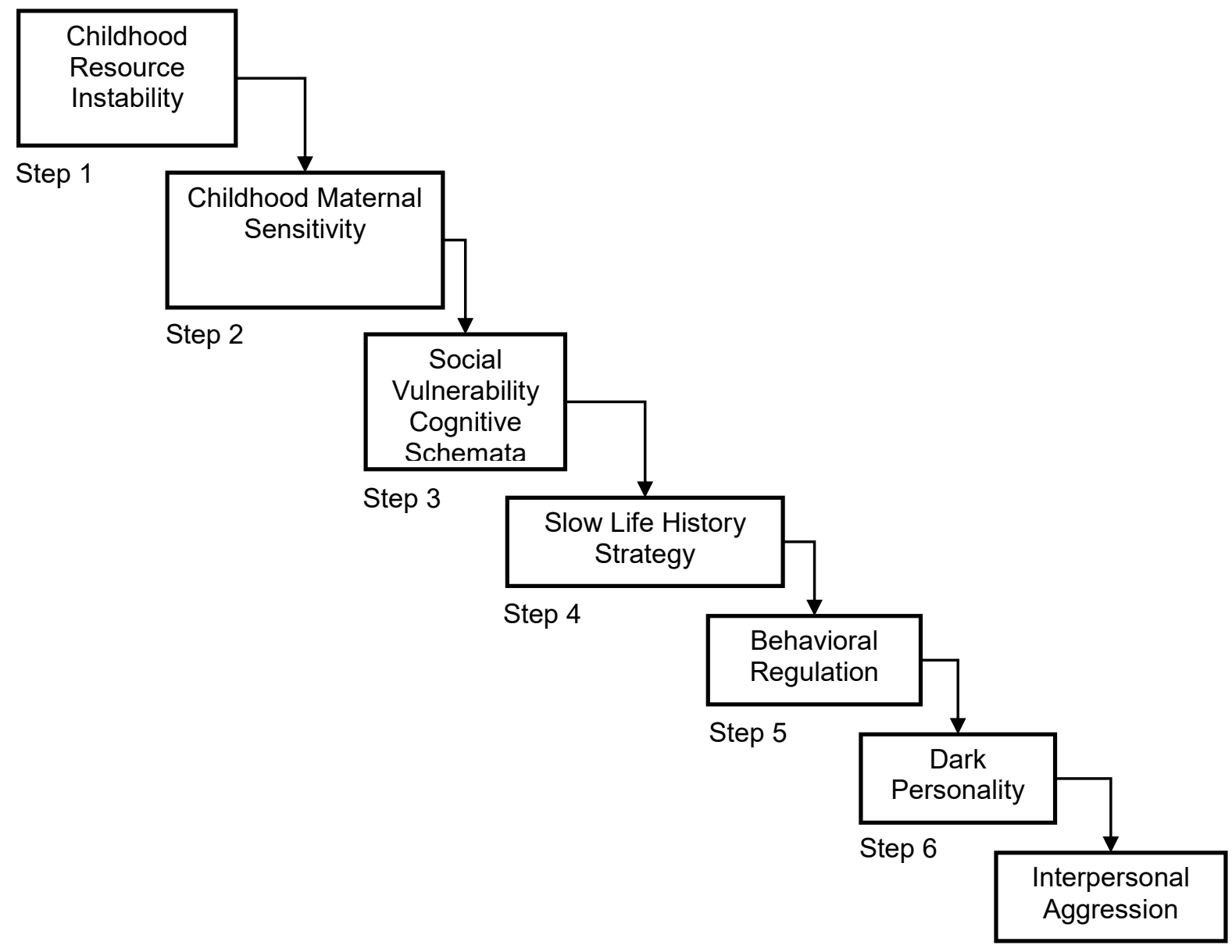

Step 7 
Figure 2.

Graphical summary of main results of the cascade model.

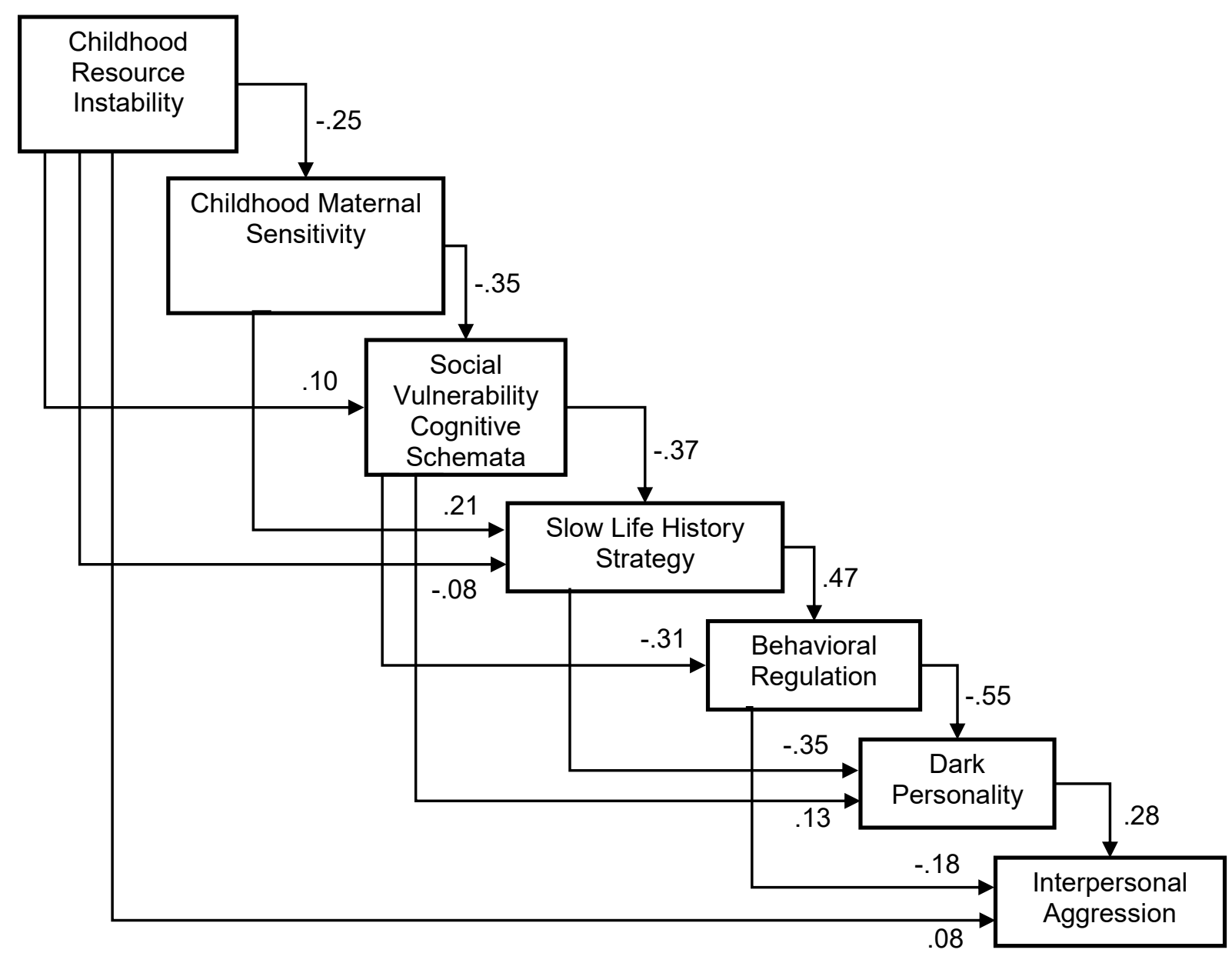


Click here to access/download

Supplemental Material

The Cascade of Chaos - Appendices A-C (EBS-R).doc 